\title{
TRANSGÊNEROS E FORÇAS ARMADAS BRASILEIRAS: Os Caminhos Para a Inclusão Social Dessas Pessoas na Sociedade Brasileira
}

\author{
Douglas Verbicaro Soares \\ Universidade Federal de Roraima (UFRR). Av. Cap. Ene Garcês, n² 2413 - Aeroporto. Boa Vista/RR, Brasil. CEP $69310-000$. \\ http://lattes.cnpq.br/0323318580034437. http://orcid.org/0000-0002-9242-9124. douglas_verbicaro@yahoo.com.br
}

RESUMO

O presente estudo versa sobre as pessoas transgêneros na sociedade brasileira, relacionando-as com a mais recente medida do governo brasileiro em incluir as pessoas transexuais (homens trans) nos processos de registro obrigatório para cidadãos homens nas Forças Armadas do Brasil. A investigação explicará algumas terminologias que fazem parte do estudo, por exemplo: a transexualidade e identidade de gênero. Dessa forma, foi empregado o método qualitativo para a investigação, por meio do estudo de materiais bibliográficos, com o objetivo de gerar uma discussão social no país sobre a transexualidade e as pessoas transgêneros. Por essa razão, essa investigação busca respostas para algumas indagações: $O$ que é a transexualidade e as pessoas transgêneros? Essas pessoas sofrem algum tipo de discriminação por sua identidade na sociedade brasileira? Qual a relação existente entre transgêneros e Forças Armadas no Brasil? Por que as medidas do governo brasileiro para o registro de pessoas transexuais masculinas foram criadas no ano de 2018? Foi uma política pensada para a efetiva regulação/incorporação de pessoas trans no serviço militar?

Palavras-chave: Transexualidade; identidade de gênero; governo brasileiro; instituições militares.

TRANSGENDER AND BRAZILIAN ARMED FORCES:

THE PATHS TO THE SOCIAL INCLUSION OF THOSE PEOPLE IN BRAZILIAN SOCIETY

ABSTRACT

The study deals with transgender people in Brazilian society, relating them to the latest measure of the Brazilian Government to include transgender people (trans men) in cases of compulsory registration for citizen's men in the armed forces of Brazil. The investigation will explain some terminology that are part of the study, such as: transsexualism and gender identity. In this way, the qualitative method was employed for research, through the study of bibliographic materials, with the aim of generating a social discussion in the country about transsexualism and transgender people. For this reason, this research seeks answers to some questions: what is transsexuality and transgender people? These people suffer some sort of discrimination by your identity in Brazilian society. What is the relationship between transgender people and armed forces in Brazil? Why the Brazilian Government's measures for the registration of people male transsexuals were created in the year 2018? It was a policy designed for effective regulation/incorporation of trans people in the military?

Keywords: Transsexuality; gender identity; the brazilian government; military institutions.

Recebido em: 10/3/2019

Aceito em: $18 / 10 / 2021$ 


\section{INTRODUÇÃO}

Este trabalho procura mostrar que todos os seres humanos, em especial as pessoas trangêneros, apesar das inúmeras diferenças biológicas e a incidência de construções socioculturais e religiosas, que ressaltam a diversidade humana, em suas características físicas/ psicológicas, distinguindo cada pessoa, merecem igual respeito, sem importar o gênero, identidade de gênero ou orientação sexual. Todos os indivíduos merecem ser tratados com igual respeito, sem a incidência de condutas discriminatórias, sobretudo dentro das Forças Armadas Brasileiras.

Nesse sentido, as pessoas transgêneros devem ser respeitadas e ter acesso aos mesmos direitos que os demais cidadãos, sem sofrer condenação social motivada por sua condição essencial, que é a de pertencer a uma diversidade humana, que amplia a própria definição de sexo, reconhecendo sua dignidade e necessária proteção/efetivação.

A diversidade humana, que é inerente à própria variante de sexualidade e de gênero, exige para seu entendimento uma conscientização social sobre a preservação das múltiplas formas existentes dessa mesma diversidade, garantindo a manutenção de preceitos de justiça, de harmonia, de paz e igualdade (MACHADO, 2004, p. 14).

A conscientização comentada implica a abertura sociocultural nos padrões que, durante séculos, alijaram de participação, na sociedade brasileira, do coletivo de pessoas transgêneros, que foram punidas por meio de violências físicas e psicológicas. Em caso análogo, Foucault expressaria a origem dessa discrição na arte de fazer sofrer mais sutilmente, de modo mais velado, mas não menos prejudicial às vítimas de condutas discriminatórias (FOUCAULT, 2016 , p. 13), fato que permitiu o tratamento desigual e injusto entre os cidadãos no país, em especial o de grupos em situação de exclusão. Desigualdades essas que se afastam do ideário instrumental do direito de resguardar a harmonia nas relações humanas (MACHADO, 2004, p. 23-24), principal ideário inclusive da preservação dos direitos humanos e sexualidade, assim como em gênero e suas identidades.

Com base nas diversas formas de discriminação e trato desigual entre os indivíduos, inúmeros autores buscaram definir a beleza que existe na diversidade dos seres humanos, no intuito da promoção da diversidade humana e de coibir condutas que contrariem esses anseios. Nesse aspecto, buscou-se evidenciar que cada pessoa é única e não menos importante que as demais. Consequentemente, que todas deveriam ser tratadas com respeito, incentivando a valorização dessa diversidade.

Nessa linha de entendimento, de acordo com Fábio Comparato, os homens seriam os únicos animais dotados da capacidade de amar, de descobrir a verdade e que nenhum indivíduo pode se considerar superior, pois todos são iguais na condição de seres humanos, apesar das inúmeras diferenças socioculturais que os rodeiam (COMPARATO, 2001, p. 1).

O objetivo deste trabalho é retratar as pessoas transgêneros na sociedade brasileira e, também, sua relação com a normativa do governo no alistamento de transgêneros homens nas Instituições Militares no Brasil. Primeiramente abordar-se-á o conceito de identidade de gênero e suas implicações no âmbito sociocultural. Desse modo, alertando a comunidade que essa condição da diversidade humana (as pessoas transgêneros) não representa um risco para a harmonia social e, sim, faz parte de uma nova etapa de convívio para a humanidade, 
baseada nas novas exigências democráticas, que valorizam o processo de reconhecimento, aceitação da diversidade e integração cidadã de grupos vítimas de exclusão social, como é o caso das pessoas trans.

De acordo com a metodologia empregada, utilizou-se uma abordagem teórica, baseada em investigação bibliográfica. Em um primeiro momento optou-se pelo estudo de gênero e suas identidades e sexo, tratando de suas terminologias. Após essas análises o trabalho segue com o anseio de relacionar a questão da transexualidade e suas implicações com a mais recente normativa do governo brasileiro quanto à regulação das pessoas transgêneros masculinas nas Forçar Armadas do Brasil. Trabalhar-se-á, em seguida, os temas de preconceitos e justificativas pela não aceitação de pessoas trans nas Instituições Militares no país.

\title{
2 OS DESAFIOS PARA A TRANSEXUALIDADE NA SOCIEDADE BRASILEIRA: AS PESSOAS TRANSGÊNEROS
}

\author{
Folks roamed the earth like big rolling kegs \\ They had two arms \\ They had two sets of legs \\ They had two faces peering \\ Out of one giant head \\ So they talked; while they read \\ And they never knew nothing of love \\ It was before the origin of love \\ (The Origin of Love)
}

O emprego, neste estudo, da obra artístico-literária "Hedwig \& The Angry Inche" é justificada pois retrata um sentimento comum mencionado pelas pessoas transgêneros, que seria a emoção que tem uma pessoa (identidade de gênero) de não se reconhecer, ou seja, não se identificar com seu corpo biológico. Nesse aspecto, no conto fictício, o personagem Hedwig passa por uma cirurgia clandestina para a adequação de seu sexo biológico à identificação psicológica como mulher, mas que sofre um desastroso resultado em sua cirurgia de redesignação sexual, popularmente conhecida como "mudança de sexo".

Se não fossem trágicas essas experiências, a situação das pessoas transgêneros agrava-se pela falta de conhecimento sobre a problemática enfrentada por essas pessoas. Por um lado, têm que se deparar com questões internas de autoconhecimento; por outro, sofrem pelo desenvolvimento de suas identidades de gênero que conflita com uma intensa imposição cultural, de uma sociedade que não é conhecedora dessa problemática, que tende a estigmatizar as pessoas trans como degenerados, promíscuos, doentes e pecadores.

De acordo com a obra, o personagem de Hedwig tem de enfrentar as dificuldades que norteiam a temática dos transgêneros, como os preconceitos e discriminações socioculturais. O sujeito fictício, de forma dramática, passa por abusos físicos sexuais e psicológicos por um familiar, tendo desde cedo que lutar para sobreviver às adversidades socioculturais impostas por uma sociedade conservadora até a idealização de um suposto amor com um militar norte-americano.

É válido mencionar que essas dificuldades caracterizam alguns dos relatos mais comuns de pessoas trans em distintas sociedades pelo mundo. Por essa razão, a temática da sétima 
arte exposta é atual para exemplificar e dar a conhecer a situação de muitas pessoas que têm de viver sua sexualidade em situações de vulnerabilidade social.

Assim, o filme "Hedwig \& The Angry Inche", do final da década de 90, se adéqua a temas relacionados com a sexualidade humana, orientação sexual, gênero e identidade de gênero. A letra da canção que inicia esse tópico: "The origin of love", busca retratar a origem do amor, segundo inspiração de Platão. Dessa forma, a letra de A origem do amor, serve como explicação mitológica e instrumento de conscientização quanto à sexualidade e à diversidade.

Com o passar dos tempos, principalmente em sociedades ocidentais, as práticas e os hábitos humanos foram constituídos em uma base predominantemente heterossexual, seja por influências religiosas e/ou socioculturais, que definiram essa variante da diversidade sexual como o modelo único a ser seguido e respeitado. Condição esta que implicou a submissão e restrição da própria diversidade a um patamar inferior, muitas das vezes obscuro e pecaminoso.

Não obstante, nas últimas décadas do século 20, a produção de estudos científicos permitiu mudanças de pensamentos sobre a transexualidade e as pessoas transgêneros, que desenvolveram nas áreas das Ciências Biológicas, principalmente, novos debates sobre o que antes era considerado como doença e depravação, foi cedendo espaço para o entendimento da questão sobre a proteção dos estudos de gênero suas identidades.

Nesse sentido, notou-se que com a evolução histórico-cultural e religiosa pelo mundo, propiciou o aprimoramento e a descoberta de novas interpretações sobre a questão da transexualidade em distintas áreas da ciência, fazendo com que as novas gerações se deparassem com sua evidenciação e aceitassem mais facilmente a diversidade inerente a cada pessoa trans. O caminho para um efetivo processo de integração desses indivíduos, porém, ainda faz parte da reivindicação do coletivo LGBTQI no Brasil e pelo mundo.

É notório que houve, principalmente nos últimos anos, uma ascensão da temática nas discussões da sociedade brasileira sobre as pessoas transgêneros, seja pelas manifestações reivindicatórias por direitos iguais ou acesso a direitos específicos, como a possibilidade de modificação do sexo biológico de uma pessoa com identidade de gênero (mediante procedimentos cirúrgicos) ou até mesmo na possibilidade de modificação do registro com um nome social que se adéque às realidades físico/psicológicas de muitos indivíduos.

Nesse aspecto, as modificações também são estendidas às orientações normativas estabelecidas pelo governo brasileiro no ano de 2018 , com a possibilidade de pessoas transgêneros masculinas pudessem se registrar nas Instituições Militares, como já ocorria com a obrigatoriedade dos homens brasileiros no serviço militar do país.

É fundamental reconhecer nesse estudo que as limitações à sexualidade e aos prazeres do sexo foram reduzidas pelos fatores criados culturalmente, os quais limitaram ao sexo masculino e ao feminino padrões comportamentais a serem seguidos socialmente, por homens e mulheres, caracterizando as práticas sexuais como condutas de dominação de um sexo sobre o outro.

De acordo com esta perspectiva teórica, o processo de sexualização dos indivíduos pode ser dividido em duas partes. Em um primeiro momento, ao nascermos, nos é atribuído um sexo biológico (macho ou fêmea). Em um segundo momento, após um processo de 


\section{Democracia}

socialização e de aprendizagem de papéis, nós adquirimos um gênero masculino, feminino ou neutro (nem masculino nem feminino). É importante salientar que, do ponto de vista médico, a normalidade foi definida através de uma coerência entre o sexo biológico e o gênero psicológico (sexo biológico masculino e gênero masculino ou sexo biológico feminino e gênero feminino). As situações de incoerência entre sexo biológico e gênero foram definidas como situações de anormalidade, sujeitas, portanto, a intervenções médicas corretivas (CYRINO, 2013, p. 95).

Padrões estes que traçam principalmente os fatores masculinos e os femininos impostos pelo meio, seja por familiares, amigos, colegas, etc., desde o nascimento de uma criança até o final de sua vida. Assim, as ações humanas são tomadas como referências por essas bases predeterminadas, que reduzem as possibilidades e limitam o comportamento humano e suas características definidoras ao restrito leque da imposição preconceituosa de determinados valores em detrimento de outros, que acabam estabelecendo fortes diretrizes que induzem à não violação dos moldados fatores masculino/feminino.

Los roles y las prácticas sexuales, que naturalmente se atribuyen a los géneros masculino y femenino, con un conjunto arbitrario de regulaciones inscritas en los cuerpos que aseguran la exploración material de un sexo sobre el otro (PRECIADO, 2011, p. 17-18).

Os problemas sofridos pelos transgêneros no Brasil, em muitos dos casos, são ocasionados pelo estabelecimento/imposição do modelo de heterossexualidade, já enraizada na sociedade, que a coloca em uma posição de destaque diante da diversidade sexual. Desse modo, acaba se constituindo como aceitável pela maioria das pessoas, como a única forma possível, natural e legítima a ser respeitada.

Por conseguinte, as pessoas que fogem aos preceitos predominantes da heterossexualidade sofrem a estigmatização social por não seguirem os preceitos de domínio de uma determinada orientação sexual (hétero) sobre as demais, homossexual ou bissexual por exemplo. Entre essas pessoas estão os transexuais/transgêneros que extrapolam a própria definição de sexo e gênero e que vivem em situação de exclusão.

Por outro lado, a designação LGBT (lésbica, gays, bissexuais, transexuais/trangêneros), apresenta também algumas desvantagens analíticas. Estes vocábulos, politicamente esgrimidos na constituição de uma política pelo reconhecimento da diversidade das identidades sexuais, aplicam-se, afinal, a indivíduos cuja demonstração de empenhamento identitário conduz ao desenvolvimento de estratégias reflexivas de inclusão numa dada categoria sociopolítica. Ser gay, lésbica ou bissexual constituem afinal rótulos que, longe de serem naturais, resultam de um longo processo histórico e político de luta pelo reconhecimento social de sexualidade construída fora da norma heterossexual dominante (ABOIM, 2010, p. 147-148).

As realidades vivenciadas pelas pessoas transexuais retratam uma problemática generalizada, que pode ter seu início em uma infância desestruturada, na qual uma pessoa trans encontra uma vasta variedade de imposições (padrões) comportamentais, previamente estabelecidos pela sociedade, e que têm a função de determinar a forma de ser e de se manifestar as ações humanas dessas pessoas (FREIRE, 1997, p. 5).

Nesse sentido, todos que não se adéquam aos preceitos impositivos da heteronormatividade, começam a ser perseguidos, questionados e discriminados ao expressar de modo 
diferente suas sexualidades, seja dentro de um núcleo familiar ou fora dele, no convívio com outras pessoas.

En todas las culturas existe un modelo normativo acerca de cómo debe ser un varón y una mujer. Estas construcciones sociales tienen un papel fundamental en la organización y constitución de la subjetividad humana. Desde la década de los setenta y bajo el liderazgo del movimiento feminista se ha realizado una gran cantidad de investigaciones en torno a la incidencia que tienen las diferentes opciones de rol de género (masculinidad, feminidad, androginia e indiferenciación) en la configuración de la identidad y en los modos específicos de enfermar (FREIRE; CARRASCO; MARTíNEZ, 2015).

As adversidades estão presentes quando padrões preestabelecidos estipulam o que seria um comportamento correto para a prática de uma determinada ação e o que seria possível como tal; são relações de poder estabelecidas entre os sexos e que são impostas, inicialmente, às crianças por seus pais ou responsáveis.

Qual é a problemática desses casos? A ausência da abordagem do tema da transexualidade gera um grave conflito na sociedade brasileira, o que repercute em um obstáculo para as ideias e definições sobre essa questão de gênero, pois muitas vezes os assuntos que versam sobre identidade de gênero acabam não recebendo a importância que a temática exige e que se vê tratada como algo que pertence a uma minoria. Essa atitude restritiva deve ser modificada para que a transexualidade passe a ser conhecida e respeitada.

Modificar essas realidades somente será possível com uma conscientização geral dessa sociedade, em que os homens, detentores de um domínio predominante, possam permitir que grupos em situação de vulnerabilidade tenham sua efetiva participação social, em igualdade de condições com os demais cidadãos. Isso é o que enfatiza o ideal republicano brasileiro de valores elementares, como o da igualdade, solidariedade, liberdade, onde existe a igual participação entre todos.

Por essa razão, são importantes os estudos sobre as relações de gênero e identidade de gênero, que englobam os temas das pessoas trangêneros e que contribuem para se compreender o sofrimento desses indivíduos, a estudar suas problemáticas de identidade de gênero e não mais vê-los como algo patológico para essas pessoas. Essas mudanças foram possíveis porque a "anormalidade" feminina e de gênero foram entendidas como uma construção da cultura patriarcal subordinantes para as mulheres que pode e deve ser desconstruída e reconstruída com uma proposta de igualdade de trato entre os gêneros (TORNS, 2008, p. 71).

O problema da discriminação agrava-se pela falta de abordagem social sobre os temas da sexualidade e identidade de gênero. Essa condição representa um grave problema para a aceitação e integração de um número grande de pessoas, que possuem uma diversidade nos padrões de gênero, mas não menos importante e que, em nenhuma hipótese, se justifica a prática de condutas violentas às pessoas transgêneros.

A violência de gênero, aparada em princípios e valores que tratam de acabar com a posição de inferioridade das mulheres, é a máxima manifestação de desigualdade entre homens e mulheres. Esta manifestação que vulnera abertamente os direitos fundamentais das mulheres, como é o direito à vida, à integridade física e psíquica, supõe uma obriga- 
ção para o governo e para os poderes públicos, para a aplicação de medidas que tornem reais e efetivos os direitos juridicamente reconhecidos, assegurando o pleno exercício de sua condição de cidadãs (GALVÁN, 2012, p. 68).

Com base nesse raciocínio, abordam-se os preconceitos e as discriminações como transmissores do ódio coletivo e violências em sociedade, que contagiam as pessoas, que as cegam e as levam à certa ignorância racional. Assim, proporcionam a consolidação das fobias (medos), em relação a tudo o que seja diferente ou ao que foi anteriormente estabelecido como o modelo correto, preestabelecido e impositivo.

É importante ressaltar que o preconceito deriva de uma ideia preconcebida, que se exterioriza por atos de discriminação entre indivíduos. Como já abordado anteriormente, o que é diferente acaba assustando, traz o medo à normalidade social estabelecida, questiona as normas vigentes e, supostamente, presume um perigo à estabilidade das normas impositivas de um grupo. Esse preconceito poderá se manifestar sob diferentes formas, nos mais variados temas, sejam eles baseados na orientação do desejo ou na raça de uma pessoa ou de grupos, assim como também relacionadas com temas cultural, social, político ou religioso.

O preconceito efetiva-se por meio de uma ideia de subjetividade, que parte de um único indivíduo ou de um grupo em relação a outrem ou a grupos em uma sociedade. Ideia essa que se consolida pelo estereótipo criado e atribuído a determinadas pessoas que acabam sendo vitimadas socialmente pelo reconhecimento de suas diversidades e pela luta de seus anseios como tal.

Por preconceito, designam-se as percepções mentais negativas em face de indivíduos e de grupos socialmente inferiorizados, bem como as representações sociais conectadas a tais percepções. Já o termo discriminação designa a materialização, no plano concreto das relações sociais, de atitudes arbitrárias, comissivas ou omissivas, relacionadas ao preconceito, que produzem violações de direitos dos indivíduos e dos grupos (RIOS, 2009, p. 54).

Quando se trabalha como os temas do preconceito e da discriminação, nota-se uma grande dificuldade de defini-los, tanto no ramo do Direito como em outras Ciências, como o da Sociologia, História, Medicina ou da Psicologia, Antropologia e muitos outros.

Esse termo, o preconceito, é antigo. Pode-se afirmar que acompanha a própria História da humanidade, está enraizado nas bases de diversas comunidades, como uma nefasta manifestação que denigre desgastando os relacionamentos humanos, dificultando a efetivação dos direitos humanos, em destaque a igualdade nos temas de relacionados com gênero e sexualidade (identidades de gênero e orientações sexuais) (VERBICARO SOARES, 2015, p. 633).

Consolidava-se, portanto, a ideia de que os direitos humanos são direitos que precisam ser respeitados por todos os Estados, e em todos os lugares, independentemente de raça, cor, religião ou nacionalidade. Na medida em que os direitos humanos, fundamentais para assegurar o respeito aos direitos básicos do homem e a sua dignidade como pessoa (FERREIRA, 2015, p. 51).

Nesse sentido, é importante a criação de um lugar onde se respeite o diverso, o diferente nos mais diversos discursos, sejam eles abordados pela definição errônea/restritiva de masculino ou feminino, abrindo espaço para a compreensão das novas masculinidades e feminidades, entendidas como a inexistência de barreiras definidoras para esses preceitos dicotômicos e excludentes. 


\section{DEFINIÇÕES RELEVANTES PARA A CONSCIENTIZAÇÃO SOBRE GÊNERO, SEXO, TRANSEXUALIDADE E PESSOAS TRANSGÊNEROS}

Para um melhor entendimento sobre os temas abordados neste trabalho, faz-se necessária a busca por algumas definições. A primeira dessas expressões relaciona-se à temática da diversidade. Diversidade essa que representa a soma de características que integram um conjunto muito mais complexo, que representa a diversidade sexual humana de forma abrangente e multidisciplinar (VERBICARO SOARES, 2011, p. 65).

A terminologia diversidade pode representar o conjunto de aspectos distintos que estão presentes em uma matéria específica, que podem ou não se relacionar em algum caso, lugar. É a utilização da ideia de amplo, assim como na utilização das diferenças para compor uma aceitação comum (KOTLINSKI; CEZÁRIO; NAVARRO, 2007, p. 40).

A diversidade sugerida, em relação à diversidade sexual, está na maneira de expressão das diversas manifestações dentro dos gêneros, em que o masculino e o feminino representam apenas limitadas características para a retratação do que seria o sexo no amplo desenvolvimento de sua própria diversidade. Um exemplo de superação desse limitado binômio masculino/feminino é o das pessoas transexuais que superam essa dicotomia e vivem entre os dois conceitos de sexo e gênero.

Para a expressão que define sexo, alguns estudos tipificam o termo como referente às características específicas e biológicas dos aparelhos reprodutores feminino e masculino, ao seu funcionamento e aos caracteres sexuais secundários decorrentes dos hormônios. O sexo determina que as fêmeas tenham vagina/vulva e os machos pênis, apenas isso. $O$ sexo não determina, por si só, a identidade de gênero, e muito menos a orientação sexual de uma pessoa (KOTLINSKI; CEZÁRIO; NAVARRO, 2007, p. 35).

Para outros autores, o sexo englobaria a expressão usada para se referir aos órgãos sexuais, à relação sexual, aos atos físicos relacionados com a reprodução sexuada) e outros comportamentos da sexualidade humana (MARTINS et al., 2010, p. 9).

Por sua vez, ao se referir a gênero, sua definição não aporta um conceito biológico. $\mathrm{Na}$ verdade seria um termo mais subjetivo, uma questão cultural e até mesmo social. Seria um empreendimento duradouro feito pela sociedade para transformar o ser nascido com vagina ou pênis em mulher ou homem (KOTLINSKI; CEZÁRIO; NAVARRO, 2007, p. 35).

De acordo com os estudos de John Money e Anke Ehrhardt, em especial com a obra "Man \& Woman, Boy \& Girl: The differentiation and dimorphism of gender identity from conception to maturity" de 1972, os autores desenvolvem a conceituação de gênero, influenciando posteriormente os estudos sobre sexualidade no século 20. Entre os ideais deixados pelos autores estariam a justificação da existência de um papel social de gênero, que influi na formação dos comportamentos humanos, em que incidem fatores convencionais sociais e que determinam as condutas a serem exercidas por homens e mulheres.

Essa interpretação permitiu a ampliação do conceito de gênero, não restringindo a sua definição a apenas uma característica restritiva de pertencer ao homem ou mulher, mas atribuir importância a um conjunto de fatores que concedem abrangência ao tema, como podem ser o reconhecimento individual e determinação do meio social no comportamento 
desenvolvido por uma pessoa, etc., que complementam a questão fisiológica sexual/genital de um sujeito na diversidade.

Nesse aspecto, destaca-se a conceituação da expressão identidade de gênero para as pessoas transgêneros, que por sua vez somam a incidência de aspectos individualizados de feminidade/masculinidade, ou ambos relacionados com a capacidade de conhecimento que cada pessoa é dotada de convencimentos racionais e, também, comportamentais em determinada sociedade.

É válido mencionar que os estudos de Money e de seus seguidores instituem a visibilidade da transexualidade e acabaram destacando o comportamento social humano, como influenciado por normas preestabelecidas em questões fisiológicas, típicas da visão sexual e genital biológica das pessoas: do macho (com pênis) e fêmea (com vagina). Assim, seus ideais rompem com essa dicotomia tradicional e sugerem novas alternativas sobre a conceituação de gênero, mostrando variantes que, até então, eram desconsideradas, como as pessoas transexuais e, da mesma forma, as hermafroditas. Um exemplo dessa tendência foi a obra "An Examination of Some Basic Sexual Concepts: The Evidence of Human Hermaphroditism", de Money, Hampson e Hampson (1955)

De maneira similar, os estudos sobre a diversidade sexual são igualmente mencionados por Money, em especial na publicação de: "Gay, Straight and In-between: The Sexology of Erotic Orientation" (1990). A elaboração dessa investigação trouxe pioneiras orientações para se estudar a sexualidade de maneira abrangente, rompendo-se com as definições conservadoras/restritivas, que perduraram durante anos, e que dividiram a compreensão sobre sexo sempre de modo conflitivo, desde um discurso heteronormativo sociocultural, histórico e religioso, que permitiram a condenação à diversidade sexual e ao prazer sexual, restringindo-o à reprodução humana.

O conceito de gênero, formulado e utilizado pela primeira vez pelo psicólogo e sexologista John Money no ano de 1955 significou, de acordo com autores como Eric Fassin (2008), Elsa Dorlin (2005) e Beatriz Preciado (2005), uma ruptura paradigmática na concepção médica norte-americana de sexo, reinante na época (CYRINO, 2013, p. 95).

Desse modo, busca-se responder a um dos questionamentos iniciais deste estudo: 0 que é a transexualidade e as pessoas transgêneros? Para essa indagação apresenta-se a interpretação que a pessoa trans encontra-se em um processo de desenvolvimento de sua identidade, ou seja, está entre um processo de autoconhecimento e autoidentificação entre o binário de gêneros - entre o masculino e o feminino.

Para essas pessoas as estipulações de padrões de gênero podem ser problemáticas, uma vez que as mesmas possuem uma identificação diversa da imposição heteronormativa de construções históricas/culturais e religiosas de determinada sociedade. Nesse aspecto, as restrições atribuídas à identificação do sexo e gênero englobam uma série de variantes que definirão a maneira de ser dessas pessoas, podendo encontrar certas denominações para esse coletivo, entre as quais estão: os travestis, drag queens e os transexuais.

Ao mencionar a temática de gênero nesse ponto, é válido explicitar que a terminologia identidade de gênero contitui uma fonte multidisciplinar, que busca abranger suas variantes no desenvolvimento da sexualidade humana. Alguns autores defendem a amplitude da ma- 
téria, arguindo, por exemplo, que: independentemente do sexo, um ser humano pode ter a identidade de gênero de mulher, de homem ou ainda outras identidades de gênero possíveis, lembrando que a identidade de gênero é uma construção social e não um signo físico ou biológico (KOTLINSKI; CEZÁRIO; NAVARRO, 2007, p. 38).

Para mudanças na compreensão das terminologias supracitadas, a partir da década de 50 pioneiros estudos desenvolvidos sobre gênero e sexualidade humana possibilitam a abertura da temática que ampliam o ideário de sexo, levando em consideração preceitos biológicos, não mais restritivos ao físico, mais também ao psicológico, dessa forma permitindo a conscientização científica sobre gênero e sexo, em especial os primeiros ensaios que buscassem explicar a manifestação da identidade de gênero, para que, mais tarde, se pudesse estudar as necessidades e dificuldades que norteiam a vida das pessoas transgêneros.

Nesse ponto destaca-se a definição de identidade de gênero para essas pessoas, ou seja, a identificação que cada pessoa tem com um tipo de gênero que se sinta melhor em desenvolver sua personalidade em dignidade.

A identidade de gênero é uma experiência interna e individual do gênero de cada pessoa, que pode ou não corresponder ao sexo atribuído no nascimento, incluindo o senso pessoal do corpo (que pode envolver, por livre escolha, modificação da aparência ou função corporal por meios médicos, cirúrgicos e outros) e outras expressões de gênero, inclusive vestimenta, modo de falar e maneirismos (MARTINS et al., 2010, p. 16).

No passado, posicionamentos conservadores condenavam essa possibilidade aos indivíduos que se encontravam insatisfeitos com sua própria característica físico-biológica e que, em muitos dos casos, eram obrigados a seguir determinados padrões comportamentais para não agredir a sociedade, pois eram considerados pessoas com transtornos mentais, que deveriam ser tradas pelas Ciências Biológicas no sentido de promoção de cura de suas supostas patologias.

Não se deve esquecer que Organismos Mundiais de Saúde orientavam os profissionais, que tratassem dessa problemática com planos justificados pela Medicina e Psicologia, contra aos sentimentos mais íntimos de uma pessoa de se ver e, principalmente, de se reconhecer ou não em um corpo físico estranho. Essa possibilidade foi negada até o século passado para muitas pessoas, que se viram obrigadas a tratar a questão da identidade de gênero como hipotética desordem mental (VERBICARO SOARES, 2015, p. 550).

Para uma visão biomédica, a identidade de gênero é prestabelecida, fixa, essencialista e consequentemente da sexualidade. A partir daí as pessoas trans serem consideradas portadoras de um transtorno (...) não é uma eleição nem um capricho, é um descobrimento; é um espaço de exploração e questionamento, é uma busca, um descobrir: as pessoas trans (travestis, transexuais e trangêneros) são historicamente apontadas como categorias de patologização ou transtornos mentais por parte de vozes médicas internacionais, como a Organização Mundial da Saúde (OMS) e o Manual de Diagnóstico e Desordens mentais (DSM) da Associação Psiquiátrica Americana (APA) (CANO; YACOVINO, 2014, p. 3).

Essa hierarquia também poderá se manifestar em relação à inferiorização de um grupo minoritário, assim como ocorre com as mulheres, exemplo: discriminação e alijamento participativo de pessoas trans em serem respeitadas e garantidas em seus direitos perante uma hierarquia machista, preconceituosa e patriarcal na sociedade brasileira. 
Desde o século 19 o discurso médico, fundamentado na heteronormatividade e no binarismo de gênero, vem normatizando as condutas sexuais e as expressões da masculinidade e da feminilidade em parâmetros de saúde/normalidade ou de doença/anormalidade. Nessa conjuntura, existem autores que salientam a importãncia de levar em conta que certos tipos de identidade de gênero são considerados meras falhas do desenvolvimento, ou impossibilidades lógicas, porque não se conformam às normas da inteligibilidade cultural vigente (SAMPAIO; COELHO, 2013, p. 5).

Após as considerações sobre diversidade e sexo, deve-se explicitar a questão do gênero, que por sua vez engloba duas tipificações destacáveis. A primeira delas tem a ver com a identificação pessoal de um indivíduo com o gênero feminino ou masculino; a outra questão versa sobre o padrão assumido dentro de determinada sociedade, que muitas vezes, por meio de construções histórico-sociais, culturais e religiosas, influenciam na maneira de ser e de se comportar das pessoas.

Para as pessoas que assumem essas posturas conflitivas, entre a vontade de ser de uma maneira e desempenhar uma atitude diversa a ela, só resta a conscientização coletiva de que os problemas que envolvem a transexualidade são muito mais graves, a partir do momento em que existe um desequilíbrio estrutural multidisciplinar em normas e preceitos que versam sobre direitos, procedimentos médicos físicos e psíquicos que dificultam o pleno desenvolvimento da diversidade humana, em especial sobre os temas de gênero.

As adversidades existentes para as pessoas trans, como tratado anteriormente, são encontradas em previsões médico-científicas de organismos internacionais que tipificaram a transexualidade como uma doença, inclusive empregando a sufixo "ismo" para corroborar essa visão de patologia. Essa orientação estava prevista na Classificação Internacional de Doenças com a numeração 10, ou seja, prevista no CID 10 da Organização Mundial da Saúde (DI NUBILA; BUCHALLA, 2008, p. 324). Mais recentemente, no mês de junho de 2018, a entidade internacional se manifestou retirando a classificação da transexualidade como doença mental relacionando-a como um transtorno de identidade de gênero (OMS, 2018).

Qual seria a relação desse preceito para a transexualidade e para as pessoas trans?

A antiga estipulação dessa condição como doença mental engloba uma série de fatores que auxiliam na estigmatização histórica dessa transexualidade pelo mundo. Esse fator desprestigiava as pessoas transexuais a partir do momento em que a consideravam uma forma de transtorno mental e de comportamento. Essa caracterização é utilizada nos discursos preconceituosos e discriminatórios que rodeiam o coletivo LGBTQI, em especial os transexuais e as pessoas transgêneros.

A explicação sobre a transexualidade está na caracterização da expressão ligada às pessoas que mudam a exteriorização de seu sexo. Dessa forma, quando se fala de homem transexual, o sentido engloba os casos de pessoas que nasceram com o sexo feminino, mas que se identificam com o gênero masculino. Do mesmo modo em que a mulher transexual é aquela pessoa que nasceu com o sexo biológico de homem, mas que tem identificação com o gênero feminino. Assim, a sexualidade dessas pessoas se plasma como a expressão de sua própria personalidade e desenvolvimento afetivo (VILAR, 2010, p. 201-202). 


\section{Democracia}

Na mesma interpretação, a construção dessa sexualidade engloba a compreensão de que as pessoas transexuais são aquelas em que o seu corpo possui as características genéticas diferentes daquelas que considera adequadas para si (LIMA, 2017, p. 19).

A transexualidade, de modo similar à homossexualidade, esteve nos discursos sociais de diversas sociedade a favor de tratamentos médicos que prometiam supostas curas para os indivíduos que se submetessem. Do mesmo modo, transexuais e homossexuais estiveram em terapias, justificadas pelas ciências da Medicina e Psiquiatria, na esperança de que essas patologias pudessem ser resolvidas. Ao contrário da homossexualidade, que foi desconsiderada como doença, a transexualidade continuou a ser tratada de modo discriminatório.

Até os anos 70, havia uma idéia que esse tipo de comportamento poderia ser revertido com terapia. Contudo, um caso interessante, divulgado, em 1973 pelo sexólogo americano John Money, veio de encontro àquela assertiva. O referido sexólogo recomendou que um dos filhos gêmeos de uma mulher americana fosse criado como menina, após ter o pênis acidentalmente amputado em uma cirurgia de fimose. Desse modo, o garoto recebeu uma vagina, hormônios femininos e terapia. Os resultados satisfatórios somente duraram até o menino completar 14 anos, eis que, a partir daí o paciente desistiu de viver como menina, reconstruiu o pênis e, tempos depois, casou-se (COSTA, 1994, p. 15).

A ciência ainda não é capaz, na atualidade, de prever quais são os fatores primordiais que influenciam nos temas de transexualidade em uma pessoa. Do mesmo modo que nas orientações sexual, diversas são as teorias que buscam explicar os motivos que levam determinadas pessoas a se identificarem com um ou outro gênero (CASTEL, 2001).

No Brasil, alguns personagens vêm marcando a sociedade quanto ao tema dos transgêneros (travestis e transexuais) e androginismos, as falecidas Rogéria e Elke Maravilha, assim como Ney Matogrosso, Eloy Iglesias, Roberta Close, Lea T, Pablo Vittar, Liniker, Jaloo, Johnny Hooker, As Bahias e a Cozinha Mineira são alguns exemplos de mudanças e anseios pela integração dos temas de gênero, identidade de gênero transexualidade/trangêneros dentro da sociedade brasileira, personagens artísticos responsáveis por romper estereótipos e ajudarem nas discussões sobre temas que versam sobre a comunidade LGBTQI.

\section{O CAMINHO PARA A MUDANCCA NA VIDA DAS PESSOAS TRANSGÊNEROS: UM PROCESSO DE CONSTRUÇÃO}

O processo para a integração real das pessoas trans passa por um momento de construção e readequação de ideias sobre o tema no Brasil, uma vez que o tema envolve complexidades a serem superadas em sociedade. É notório que a visibilidade da transexualidade foi intensificada, principalmente nas últimas décadas.

A problemática vivida pelas pessoas trans tem sua origem em questões de desenvolvimento emocional/psicológico, que em muito dos casos, desde muito cedo, sofrem a influência de padrões sociocomportamentais que inibem a forma com que essas pessoas têm de expressar seus sentimentos. Consequentemente, por meio de pressões do meio (familiar, social, cultural, religiosa), acabam interiorizando um sentimento de não aceitação e questionamento, que pode influir de modo negativo na vida de muitos indivíduos transexuais. 
Los problemas de los transexuales surgen desde la infancia, con la represión de su desarrollo emocional, ejercida normalmente por sus familias y resto de la sociedad. De esta forma la persona transexual vive sometida a una constante y tremenda presión social, lo cual, unido al habitual sufrimiento por sentirse encerrado en un cuerpo que no le corresponde, afecta en mayor o menor grado a su desarrollo y personalidad (LIMA, 2017, p. 76).

Os meios de comunicação, juntamente com obras de ficção, expõem situações e personagens que refletem as realidades vividas por muitas pessoas, que durante muito tempo formam excluídas de participação social. A mudança de pensamento pode ser atestada com o destaque de personagens transgêneros que chamaram a atenção no Brasil para os problemas enfrentados pelas pessoas trans.

Mais recentemente, na obra da escritora Glória Perez, a teledramaturgia brasileira mostrou alguns problemas enfrentados pela comunidade LGBTQI. Figuras como o jovem Ivan (que descobre sua identidade de gênero aprisionado no corpo feminino de Ivana), a história do motorista Nonato, que retratou a vida dos travestis e drag queens e que demonstrou as dificuldades desses artistas em conciliar suas vidas com os preconceitos sociais. Exemplos fictícios que contribuíram para discussões sobre o tema em sociedade.

A exposição midiática dessas questões pode influir no modo de pensar sobre a diversidade sexual, nos temas de gênero e orientação sexual. Desse fato, pode-se atestar que o êxito desses personagens é baseado em uma mudança sobre a questão da transexualidade na sociedade brasileira.

Essa realidade, porém, é bastante diferente da aversão ao tema que prevalecia até o final do século 20. Aversão essa que considerava a intervenção da Medicina nos casos de transexualidade como antiéticas, amorais e criminosas, sendo condenadas tanto pelas Ciências Biológicas como na esfera jurídica no Brasil. Foi a partir de 1997 que o Conselho Federal de Medicina, pela Resolução 1.482/1997, regulava a questão como "transexualismo", orientando os profissionais da saúde em detectar os casos a serem tratados pela Medicina dos sujeitos que deveriam passar por procedimentos médicos.

Posteriormente, outras orientações do CFM foram criadas, por exemplo a Resolução no $1.652 / 2002$, que ampliava o tratamento para pessoas transexuais e os procedimentos transgenitais (ARÁN, 2008, p. 1). Já no ano de 2008 o governo brasileiro, pela Portaria 1.107/2008, introduzia no Sistema Único de Saúde o procedimento de transição em centros de referência (SILVA, 2012). Atualmente os procedimentos que permitem a transição de gênero passam por etapas de intervenções da Medicina e Psiquiatria, justamente para se enquadrarem à realidade da vida das pessoas transexuais.

No âmbito do Direito, o reconhecimento legal e a possibilidade de alteração do registro civil de nome e sexo passaram de uma proibição para uma inicial dependência de autorização judicial para se permitir a alteração dos dados dessas pessoas. Mais recentemente, por meio de decisão do Supremo Tribunal Federal em 2018, foi autorizado que as pessoas transexuais pudessem realizar a mudança cadastral de nome e sexo nos registros de nascimento, sem a exigência de ter realizado o procedimento de mudança de sexo. Essa condição representava uma antiga reivindicação do coletivo LGBTQI em termos de acesso aos mesmos direitos para todos, sem preconceitos e discriminações. 


\section{Democracia}

Dessa forma, buscou-se a resposta da seguinte indagação neste estudo: Essas pessoas sofrem algum tipo de discriminação por sua identidade na sociedade brasileira? Essa questão será abordada no tópico seguinte, que trata da evidenciação científica e didática dos estudos sobre a transexualidade.

Parece que o termo gênero é bastante controvertido, assim como qualquer matéria que se relaciona com ele. Esse tema surge na década de 70, influenciado pelo movimento feminista. Foi fruto de uma preocupação em se distinguir a esfera biológica do ramo social, partindo do princípio de que, em sociedade existem os machos e fêmeas na espécie humana (RAMON; FERRÉ, 2000-2001, p. 120).

Por outro lado, a forma de ser um homem ou uma mulher é originária do fator cultural. Significa dizer que os fatores biológicos nem sempre podem ser utilizados para determinar as características comportamentais das pessoas, pois essas características irão se adequando às realidades comportamentais na sociedade. Nesse sentido os estudos feministas, junto com os da comunidade LBGTQI, abriram precedentes para questionamentos sobre a situação de grupos excluídos de participação.

Após esses sucintos relatos e explicações terminológicas torna-se possível adentrar nas questões próprias da inserção das pessoas transgêneros na sociedade brasileira. Nesse aspecto, buscar-se-á evidenciar se essas pessoas, de acordo com as orientações do governo brasileiro, poderão ser tratadas em condição de igualdade em relação aos demais cidadãos quanto ao reconhecimento de direitos, em especial na esfera militar.

\section{FORÇAS ARMADAS BRASILEIRAS E A PREVISÃO CONSTITUCIONAL: REQUISITOS PARA O ALISTAMENTO MILITAR DE TRANSGÊNEROS MASCULINOS}

Também se percebe a explícita e tão presente questão do respeito incondicional à hierarquia e ao respeito estrito às normas da instituição (disciplinares), que condicionaram toda a vida e profissão de um militar.

De acordo com o artigo 142 da Constituição da República Federativa do Brasil, de 1988, as Forças Armadas, constituídas pela Marinha, pelo Exército e pela Aeronáutica, são instituições nacionais permanentes e regulares, organizadas com base na hierarquia e na disciplina, sob a autoridade suprema do presidente da República, e destinam-se à defesa da pátria, à garantia dos poderes constitucionais e, por iniciativa de qualquer destes, da lei e da ordem.

Com base nessas ideias, está clara a situação de imposição unilateral das organizações militares em relação aos seus membros, fato esse que impossibilitaria qualquer manifestação contrária aos padrões estabelecidos anteriormente nas Forças Armadas: Exército Brasileiro "Características da profissão militar: b. Sujeição a preceitos rígidos de disciplina e hierarquia" (EXÉRCITO BRASILEIRO, 2018).

Por outro lado, a história demonstrou que os valores sociais e culturais se modificaram, ao longo da evolução natural humana e, com isso, tendências surgiram que alteraram a barreira do intolerante e do impossível. As primeiras barreiras vêm sendo removidas para a incorporação de transexuais nas Forças Armadas Brasileiras, mas continua sendo inegável a existência de problemas estruturais que dificultam a vida das pessoas transexuais. 
O caminho é complicado, cheio de condutas que ridicularizam por condição de gênero e orientação sexual, dotadas de preconceitos, que acabam fazendo com que muitas pessoas desistam de fazer parte do quadro de integrantes de um órgão militar, ou que acabem sendo perseguidas dentro das instituições militares após revelar sua orientação sexual, no caso dos homossexuais (FIGUEIREDO, 2008, p. 154). Nada muito distante da luta diária das pessoas que buscam uma autoaceitação de sua condição (por possuírem uma identidade de gênero diversa), como de serem aceitas por familiares, amigos, em geral, pela sociedade.

De acordo com previsão das instituições militares no país, as pessoas transgêneros masculinas, ou seja, os indivíduos que nasceram com o sexo biológico feminino, mas que se identificam com o gênero masculino, e que tenham realizado a mudança no registro civil de seus dados pessoais, passam a ter a obrigatoriedade de realizar o alistamento militar. A previsão baseia-se no Decreto no 8.727, de 28 de abril de 2016, que trata do uso do nome social e o reconhecimento da identidade de gênero de pessoas travestis e transexuais no âmbito da administração pública federal direta, autárquica e fundacional.

Para esses cidadãos, as Forças Armadas estabelecem o período de 30 dias, após a realização dos procedimentos de alteração do registro civil, para que possam procurar uma das organizações militares e regularizar sua situação junto ao serviço militar obrigatório para homens (GOVERNO DO BRASIL, 2018a). Essa orientação está prevista no Decreto no 57.654/66, que trata sobre a previsão da lei do serviço militar. De acordo com a orientação, em seu artigo 41, §1으:

Art. 41.0 alistamento constitui o ato prévio, e obrigatório, à seleção.

§1ㅇ A apresentação obrigatória para o alistamento será feita dentro dos primeiros seis meses do ano em que o brasileiro completar 18 (dezoito) anos de idade. Quanto àqueles que sejam voluntários para a prestação do Serviço Militar inicial, poderá ser feita a partir da data em que o interessado completar 16 (dezesseis) anos de idade. Quanto aos brasileiros naturalizados ou por opção, deverá realizar-se dentro do prazo de 30 (trinta) dias, a contar da data em que receberem o certificado de naturalização ou da assinatura do termo de opção.

Para as pessoas transgêneros femininas, ou seja, as pessoas que nasceram com o sexo biológico masculino, mas que se identificam com o gênero feminino, e que realizaram a transição de mudança no registro civil de seus dados pessoais antes de completarem a idade de 18 anos, para elas a obrigatoriedade do alistamento militar deixa de existir. Na hipótese de realização da mudança no registro civil, após completados os 18 anos, a mesma obrigatoriedade será extinta. Esses procedimentos equiparam-se à não obrigatoriedade do alistamento militar para as mulheres no Brasil.

Dessa forma, questiona-se os motivos da necessidade do alistamento militar para as pessoas transgêneros masculinas. Sabe-se que o documento que atesta o registro individual de um homem em uma instituição militar permite que este tenha acesso a direitos. A falta do documento implica restrições graves aos cidadãos homens, por exemplo: para tirar passaporte, firmar contratos com as esferas do governo, possibilidade de realizar concursos e se inscrever em instituições de ensino públicas, ou de fazer registro em entidades profissionais, até mesmo na impossibilidade de receber premiações, etc. 
O brasileiro que não se alistar no prazo previsto estará em débito com o Serviço Militar na situação de "fora do prazo". Ao não estar em dia com as suas obrigações militares, o cidadão não poderá:

Obter passaporte ou prorrogação de sua validade;

Ingressar como funcionário, empregado ou associado em instituição, empresa ou associação oficial, oficializada ou subvencionada;

Assinar contrato com o Governo Federal, Estadual, dos Territórios ou Municípios;

Prestar exame ou matricular-se em qualquer estabelecimento de ensino;

Obter carteira profissional, registro de diploma de profissões liberais, matrícula ou inscrição para o exercício de qualquer função e licença de indústria e profissão;

Inscrever-se em concurso para provimento de cargo público;

Exercer, a qualquer título, sem distinção de categoria ou forma de pagamento, qualquer função pública ou cargo público, eletivos ou de nomeação;

Receber qualquer prêmio ou favor do Governo Federal, Estadual, dos Territórios ou Municípios (GOVERNO DO BRASIL, 2018b).

Por esses motivos elencados, a obrigatoriedade do serviço militar para homens, seja para nascidos com o sexo masculino ou para os que se identificam como tal, e que tenham procedido com a modificação de seus registros civis, se vêm impelidos a proceder com o alistamento nas instituições militares para ter regularizado o acesso aos mesmos direitos e obrigações (ALISTAMENTO ON-LINE, 2018).

\section{A TRANSEXUALIDADE E AS PESSOAS TRANSGÊNEROS NAS FORÇAS ARMADAS BRASILEIRAS}

A questão das pessoas transgêneros no país ainda é vista socialmente como um grave problema moral. Para alguns, constitui uma desordem, enfermidade, uma constante ameaça à integridade e harmonia dos considerados "normais" ou heterossexuais predominantes.

Esses valores continuam presentes nos discursos de não aceitação de indivíduos transgêneros nas esferas sociocultural e religiosa do país. Fortes são os preconceitos e ideias estigmatizadores que justificam a exclusão dos indivíduos transgêneros. Nesse momento, se buscará responder à terceira pergunta do estudo: Qual a relação existente entre transgêneros e Forças Armadas no Brasil?

Para contestar essa indagação será pertinente a seguinte exemplificação, que retrata de maneira resumida a ideia que muitos heterossexuais (homens e mulheres) têm sobre os transgêneros. Para eles, o desconhecimento generalizado sobre a temática de gênero, identidades de gênero e orientação sexual pauta as reações discriminatórias desencadeadas ao longo dos séculos no Brasil.

Entre os discursos inflamados de intolerância está o que as pessoas trangêneros representariam um risco para a integridade, a moral e os bons costumes dos valores religiosos cristãos. Valores que não consideram a diversidade sexual e misturam, erroneamente, as características distintas de cada uma dessas diversidades existentes, mas não menos importantes que a superior valoração da heteronormatividade.

Em meio às falas de intolerantes para a aceitação de pessoas transgêneros, nas organizações militares no país, estão as que afirmam que todos os transgêneros são homossexuais e, sendo assim, não seriam indivíduos capazes de controlar seus impulsos sexuais em relação 
às pessoas de sexo biológico com as quais possuem identificação, ou seja, um suposta condição que atestaria um descontrole quanto à possibilidade de "cantadas" e investidas de uma pessoa transgênero a um militar heterossexual, como se não houvesse distinção entre identidade de gênero e orientação sexual.

Também são atribuídos desqualificadores da moral e da ética, que ressaltam hipotética perversão e promiscuidade às características comportamentais de pessoas transgêneros, que inviabilizam a sua possibilidade de assumir responsabilidades, de obedecer hierarquicamente a um superior e normas institucionais. Condutas que impediriam, sobremaneira, o exercício da atividade militar por uma pessoa transgêneros.

De acordo com os estudos de Maria Celina D’Araujo, que serão utilizados de modo análogo à transexualidade, a autora, já nos finais da década de 90 , retratava que a homossexualidade e a condição das mulheres, dentro das instituições militares no país, passam por momentos de discussão e de grandes polêmicas (D'ARAUJO, 2008).

No mesmo sentido, na obra literária de Caio Fernando Abreu, Sargento Garcia, que retratava a experiência sexual de um jovem ao alistar-se no Exército com um militar, já retratava de modo fictício o tabu, o preconceito e a discriminação à homossexualidade nas instituições militares do Brasil (ABREU, 1986, p. 83-84).

Félix López Sánchez vai mais além, citando que as falsas crenças e preconceitos estão enraizados em pensamentos que alegam que os homossexuais não são pessoas trabalhadoras, que constituem um grupo de risco por suas práticas sexuais perigosas (SÁNCHEZ, 2006, p. 33-34), que muitos gays ou lésbicas dedicam-se à prostituição, que a homossexualidade representa um contágio e que seria uma temeridade para as crianças ou adultos uma vivência conjunta e em alguns casos, é justificada a eliminação dessas pessoas por grupos mais radicais e que pregam a intolerância (CASOY, 2017, p. 23).

Anos mais tarde a inclusão de mulheres nas Forças Armadas e a redução dos "tetos de cristais", ou seja, de impedimentos sofridos por elas, na ascensão aos cargos de liderança militares, parecem estar sofrendo diminuição dos obstáculos nas Forças Armadas, que inviabilizavam que as mulheres chegassem a ocupar os mesmos cargos de confiança que seus companheiros do sexo oposto.

Quanto aos homossexuais (gays e lésbicas), também lograram determinados avanços quanto à integração de pessoas com essa orientação sexual dentro das organizações militares no país. Exemplos são o reconhecimento de direitos aos homossexuais, como integração de companheiros de mesmo sexo a benefícios e determinados direitos. Por outro lado, também se deve mencionar que questões de direito ainda não foram resolvidas, pois continua efetiva normativa da época do governo militar - Código Penal Militar de 1969 (artigo 235) - que explicita a condenação da homossexualidade como conduta a ser perseguida.

Artigo 235. Praticar, ou permitir o militar que com ele se pratique ato libidinoso, homossexual ou não, em lugar sujeito à administração militar:

Pena - detenção de seis meses a um ano.

A necessidade de acompanhar as novas exigências democráticas de inclusão e aceitação da diversidade humana culminou em reivindicações do coletivo LGBTQI, junto a sociedade civil organizada e agentes públicos, no sentido de promoção de políticas para a real parti- 
cipação cidadã de coletivos em situação de vulnerabilidade. Os questionamentos quanto à previsão discriminatória do Código Penal Militar segue, com a promessa de modificação do respectivo artigo, prevista no projeto de Novo CPM.

Por conseguinte, para os temas das mulheres em gênero, dos homossexuais quanto à diversidade sexual e, mais recentemente dos transgêneros sobre as identidades de gênero, corroboram para a formação de alternativas para a proteção dos direitos desses coletivos que continuam sendo vítimas de preconceitos e discriminação na sociedade brasileira, em especial no âmbito das Forças Armadas.

\section{CONSIDERAÇÕES FINAIS}

Faz-se necessária a busca de instrumentos para a educação nos temas de gênero, identidades de gênero e diversidade sexual, para que a sociedade brasileira como um todo possa entender as problemáticas vividas pelas pessoas LGBTQI e, dessa forma, identificar e combater as práticas de preconceito e discriminação, respeitando a diversidade sexual e efetividade dos direitos humanos no país, em especial nas Forças Armadas.

Por essa razão, será importante uma real implicação de toda a comunidade em estratégias para que esses anseios não fiquem apenas em desejos e sim, que possam ser concretizados como uma tarefa comum em liberdade e na igualdade de oportunidades, sem sofrer preconceitos e discriminações contra a transexualidade e as pessoas transgêneros (MARCON; PRUDÊNCIO; GESSER, 2016, p. 298).

O tema das pessoas transgêneros nas Forças Armadas é complicado. Ainda é precoce, pois não se encontrou nenhum caso de pessoas transgêneros masculina que tenha ingressado nas Forças Armadas Brasileiras para a realização do trabalho militar, após a possibilidade de registro no alistamento militar de 2018 para pessoas transgêneros masculinas.

No sentido oposto, existem denúncias de militares que realizaram procedimentos para a modificação do sexo ou que exprimiram o desejo de realizá-los e que foram supostamente excluídos do serviço ativo do quadro de funcionários. Para alguns desses casos, o Ministério Público Federal fez recomendações ao Comando Militar e pediu providências para o combate às condutas discriminatórias e à transfobia nos quartéis.

Entre as sugestões estariam a não consideração da transexualidade como fator de reforma de militares e/ou incapacitante para o desempenho do serviço militar, a criação de programas de reabilitação ou transferência de militares trans para ocuparem outros cargos e coibir políticas internas que excluam das instituições militares pessoas transgêneros (Inquérito Civil no 1.30.001.00052/014-11 - Notificação/recomendação PRDC/RJ/No 04/2017 de 21 de novembro de 2017).

Assim, questiona-se as reais intenções do governo brasileiro para o registro de pessoas transexuais masculinas no ano de 2018. Foi uma política pensada para a efetiva regulação/ incorporação de pessoas trans no serviço militar?

A criação da normativa do governo brasileiro, que determinou o alistamento desses indivíduos nas instituições militares, traça situações que indicam que a política nacional passa pela intenção de mero cumprimento obrigacional do alistamento para pessoas transgêneros 
masculinas, para que possam regular suas informações de modo condizente com a modificação de seus registros nos registros civis.

Por outro lado, o alistamento até o momento é reduzido na certificação de dispensa do reservista do serviço militar, ou seja, sugere que a medida apenas foi criada para que os transgêneros masculinos possam conseguir o documento de reservista para não se depararem com obstáculos, já mencionados anteriormente, caso não tenham o comprovante de alistamento militar e carteira de dispensa do serviço militar obrigatório para homens.

Foi vislumbrado, neste estudo, que a questão das pessoas transgêneros dentro da sociedade brasileira, em especial com as Forças Armadas, se relaciona com a compreensão errônea, que muitas pessoas têm sobre a suposta impossibilidade ou incompatibilidade para o desempenho da atividade militar e a impossível convivência entre heterossexuais (homens e mulheres) e transgêneros, uma vez que a existência de discursos transfóbicos alimentam a rejeição a esse coletivo em situação de vulnerabilidade social no país.

Dessa forma, a incorporação não apenas dos homossexuais nas Forças Armadas, assim como de pessoas LGBTQI ainda é vista socialmente como uma suposta desvantagem. Não obstante, na última década, a situação das pessoas desse coletivo vem sendo visibilizada e, também, esforços vêm sendo implementados para a mudança de paradigmas. Destarte, a situação dos trasgêneros nas Forças Armadas poderá ainda ser modificada, seja a favor da real incorporação de pessoas transgêneros em servir as instituições de defesa nacional, tanto transgêneros masculinos como também os femininos, que até então estão dispensados da obrigatoriedade do alistamento, e de modo negativo sem a possibilidade concreta de servir como militar.

É válido mencionar que não existe proibição específica que verse sobre os transgêneros em servirem nas organizações militares, mas existe um rechaço social, como uma barreira, que impede que uma pessoa trans possa integrar os quadros de militares.

De maneira adversa, também poderá ser instituída prática que reformule a política de alistamento de pessoas transexuais masculinas nos registros militares de alistamento, uma vez que se faz presente reivindicações conservadoras, que impossibilitariam a inclusão de coletivos vitimados, ao longo dos anos, de qualquer acesso a direitos e a tratamento igualitário, mas que para os que têm esperança podem ser objeto de lutas por melhores condições de vida e respeito nas esferas dos poderes Legislativo, Executivo ou Judiciário brasileiros.

\section{REFERÊNCIAS}

ABOIM, S. Homossexualidade e bissexualidade: práticas, atracção e orientação sexual. In: FERREIRA, P. M.; CABRAL, M. V. (org.). Sexualidades em Portugal: comportamentos e riscos. Lisboa, Portugal: Editorial Bizâncio, 2010. p. 147-200.

ABREU, C. F. Sargento Garcia. In: ABREU, C. F. Morangos mofados. São Paulo: Círculo do Livro, 1986. p. 81-98.

ALISTAMENTO ON-LINE. Dúvidas frequentes. 2018. Disponível em: https://www.alistamento.eb.mil.br/help/faq. action. Acesso em: 19 abr. 2018.

ARÁN, M. Transexualidade e políticas de saúde pública no Brasil. FAZENDO GÊNERO, 8 - Corpo, Violência e Poder. 2008. Florianópolis, 25 a 28 de agosto, 2008. Disponível em: http://www.fazendogenero.ufsc.br/8/sts/ST40/ Marcia_Aran_40.pdf. Acesso em: 21 mar. 2018.

CANO, J. E.; YACOVINO M. L. Identidad de género. Comparación crítica entre la ley española y la ley argentina. JORNADAS DE GÉNERO Y DIVERSIDAD SEXUAL, 1. - Políticas Públicas e Inclusión en las Democracias Contemporáneas. Facultad de Trabajo Social, UNLP, 24 y 25/10/2014. ISBN: 978-950-34-1154-4. Disponível em: 
http://www.trabajosocial.unlp.edu.ar/articulo/2014/10/15/mesa_5_la_normativa_del_genero_, acessado em: 08/02/2018. 2014.

CASOY, I. Arquivos serial killers: louco ou cruel. Rio de Janeiro: Darkside Books, 2017. 715 p.

CASTEL, P. H. Algumas reflexões para estabelecer a cronologia do "fenômeno transexual" (1910-1995). In: Revista Brasileira de História, São Paulo, v. 21, n. 41, 2001. ISSN 1806-9347. Disponível em: http://www.scielo.br/ scielo.php?script=sci_arttext\&pid=S0102-01882001000200005. Acesso em: 15 fev. 2008.

COMPARATO, F. K. A afirmação histórica dos direitos humanos. São Paulo: Ed. Saraiva, 2001. p. 488.

COSTA, R. P. Os onze sexos: as múltiplas faces da sexualidade humana. São Paulo: Editora Gente, 1994. 218 p.

CYRINO, R. A produção discursiva e normativa em torno do transexualismo: do verdadeiro sexo ao verdadeiro gênero. In: Revista Crítica e Sociedade: Revista de Cultura Política, Uberlândia, v. 3, n. 1, p. 92-108, ago. 2013. ISSN:2237-0579.

D’ARAUJO, M. C. Mulheres, homossexuais e Forças Armadas no Brasil. 2008. Disponível em: http://www.migaIhas.com.br/arquivo_artigo/art20080618-1.pdf. Acesso em: 21 mar. 2018.

DI NUBILA, H. B. V.; BUCHALLA, C. M. O papel das classificações da OMS, CID e CIF nas definições de deficiência e incapacidade. In: Revista Brasileira de Epidemiologia, 11(2), p. 324-35, 2008.

EXÉRCITO BRASILEIRO. Características da profissão militar. Disponível em: http://www.eb.mil.br/caracteristicas-da-profissao-militar. Acesso em: 21 mar. 2018.

FERREIRA, V. R. A exploração do trabalho infantil na produção de carvão vegetal no Brasil: uma análise do estado do Pará. Salamanca, Espanha. 2015. 425 p. Tese (Doutoral) - Universidade de Salamanca - USAL, 2015.

FIGUEIREDO, F. A. Soldados não choram: a vida de um casal homossexual no Exército do Brasil. São Paulo: Editora Globo, 2008. 198 p.

FOUCAULT, M. Vigiar e punir. Petrópolis: Editora Vozes, 2016. 302 p.

FREIRE. A. G. M. Análisis de los estereotipos de rol de género. Validación transcultural del inventario del rol sexual. 1997. 633 p. Tese (Doutoral) - Universidad Pontificia de Comillas, Madri, Espanha, 1997.

FREIRE. A. G. M.; CARRASCO M. J.; MARTÍNEZ, M. P. La autoestima y los estereotipos de rol de género. Comillas, Espanha: Universidad Pontifícia Comillas. 2015. Disponível em: https://pt.scribd.com/document/19713688/La-Autoestima-y-Los-Estereotipos-de-Rol-de-g-c9nero. Acesso em: 16 fev. 2018.

GALVÁN, C. S. Principio de igualdad y transversalidad de género. Madri, Espanha: Editorial Dykinson, 2012. 255 p.

GOVERNO DO BRASIL. Homens transgêneros também devem fazer alistamento militar. 2018a. Disponível em: http://www.brasil.gov.br/defesa-e-seguranca/2018/02/homens-transgeneros-tambem-devem-fazer-alistamento-militar. Acesso em: 16 abr. 2018.

GOVERNO DO BRASIL. Tire suas dúvidas sobre alistamento militar. 2018b. Disponível em: http://www.brasil.gov. br/defesa-e-seguranca/2014/02/tire-suas-duvidas-sobre-o-alistamento-militar. Acesso em: 4 maio 2018.

KOTLINSKI, K.; CEZÁRIO, J.; NAVARRO, M. Legislação e Jurisprudência LGBTTT. Brasília: Instituto de Bioética, Direitos Humanos e Gênero; Associação Lésbica Feminista de Brasília Coturno de Vênus, 2007. 320 p.

LIMA, E. V. La transexualidad en la obra cinematográfica de Almodóvar: Todo sobre mi madre. 2017. 543 p. Tese (Doutoral) - Universidade Complutense de Madri, Madri, Espanha, p. 2017.

MACHADO, H. B. Introdução ao estudo do direito. São Paulo: Editora Atlas, 2004. 244 p.

MARCON, A. N.; PRUDÊNCIO, L. E. V.; GESSER, M. Políticas públicas relacionadas à diversidade sexual na escola. In: Psicologia Escolar e Educacional, São Paulo, v. 20, n. 2, p. 291-301, maio/ago. 2016.

MARTINS, F.; ROMÃO, L.; LINDNER, L.; REIS, T. Manual de comunicação LGBT: lésbicas, gays, bissexuais, travestis e transexuais. Brasília: ABGLT - Associação Brasileira de Lésbicas, Gays, Bissexuais, Travestis e Transexuais, 2010. $52 \mathrm{p}$.

MINISTÉRIO PÚBLICO FEDERAL. Notificação/recomendação PRDC/RJ/No 04/2017. 2017. Disponível em: http:// www.mpf.mp.br/rj/sala-de-imprensa/docs/pr-rj/recomendacao-transexuais-forcas-armadas. Acesso em: 26 abr. 2018.

MONEY, J.; HAMPSON, J. G.; HAMPSON, J. An Examination of Some Basic Sexual Concepts: The Evidence of Human Hermaphroditism. Johns Hopkins Hosp, EUA: Bull Johns Hopkins University, 97 (4), p. 301-319, 1955.

MONEY, J. Gay, Straight and In-between: The Sexology of Erotic Orientation. Oxford, EUA: Oxford University Press, 1990. $288 \mathrm{p}$.

MONEY, J; EHRHARDT, A. Man \& Woman, Boy \& Girl: The differentiation and dimorphism of gender identity from conception to maturity. Northvale, EUA: Jason Aronson Inc. Publishers, 1972. 311 p. 
OMS. Organización Mundial de la Salud. La Organización Mundial de la Salud (OMS) publica hoy su nueva Clasificación Internacional de Enfermedades (CIE-11). 2018. Disponível em: http://www.who.int/es/news-room/detail/ 18-06-2018-who-releases-new-international-classification-of-diseases-(icd-11). Acesso em: 20 jun. 2018.

PRECIADO, B. Manifiesto contrasexual. Barcelona, Espanha: Editorial Anagrama, 2011. 210 p.

RAMON, M. D. G.; FERRÉ, M. B. El nuevo papel de las mujeres en el desarrollo rural. In: Documents D'Anàlisi Geogràfica, Barcelona, Espanha: Oikos-Tau, n. 38, p. 159-164, 2000-2001. ISSN 0212-1573, ISSN-e 2014-4512.

RIOS, R. R. Homofobia na perspectiva dos Direitos Humanos e no contexto dos estudos sobre preconceito e discriminação. In: JUNQUEIRA, R. D. Diversidade sexual na educação: problematizações sobre a homofobia nas escolas. Brasília, Brasil: Ministério da Educação; Secretaria de Educação Continuada; Alfabetização e Diversidade; Unesco, 2009. p. 53-83. (Coleção educação para todos).

SAMPAIO, L. L. P.; COELHO, M. T. A. D. A transexualidade na atualidade: discurso científico, político e histórias de vida. Salvador, Brasil. 2013. Disponível em: https://repositorio.ufba.br/ri/bitstream/ri/15770/1/A\%20TRANSEXUALIDADE\%20NA\%20ATUALIDADE.pdf. Acesso em: 15 fev. 2018.

SÁNCHEZ, F. L. Homosexualidad y família. Lo que los padres, madres, homosexuales y profesionales deben saber y hacer. Barcelona, Espanha: Editorial Graó, 2006. 166 p.

SILVA, S. V. M. Transexualidade e discriminação no mercado de trabalho. Brasil. 2012. Disponível em: http:// www.egov.ufsc.br/portal/conteudo/transexualidade-e-discrimina\%C3\%A7\%C3\%A3o-no-mercado-de-trabalho. Acesso em: 19 fev. 2018.

TORNS, T. El trabajo y el cuidado: cuestiones teórico-metodológicas desde la perspectiva de género. In: Empiria Revista de Metodología de Ciencias Sociales, Madri, Espanha, n. 15, p. 53-73, enero/jun. 2008. ISSN: 1139-5737. VERBICARO SOARES, D. Homossexualidade e Forças Armadas. A busca pela efetividade dos Direitos Humanos no Brasil. Salamanca, Espanha. 2011. 233 p. Tesina (Grado da Usal) - Universidade de Salamanca - Usal, 2011.

VILAR, D. Desempenho sexual - satisfação e problemas. In: FERREIRA, P. M.; CABRAL, M. V. (org.). Sexualidades em Portugal: comportamentos e riscos. Lisboa, Portugal: Editorial Bizâncio, 2010. p. 201-230. 